\title{
FEATURES OF CATALYTIC HYDROCARBON COMBUSTION SYSTEM WITH CO-DIRECTIONAL MOVEMENT OF FILLER AND BURNING GAS
}

\author{
Yuri Nikolaevich Sidyganov \\ Volga State University of Technology, Russian Federation \\ Evgeny Mikhailovich Onuchin \\ Volga State University of Technology, Russian Federation \\ Andrey Andreevich Medyakov \\ Volga State University of Technology, Russian Federation \\ Denis Mihailovich Lastochkin \\ Volga State University of Technology, Russian Federation \\ Alexandr Dmitrievich Kamenskih \\ Volga State University of Technology, Russian Federation
}

Current designs of catalytic systems have their drawbacks, primarily connected with insufficiently intensive usage of expensive catalytic filler. To increase the intensity of the hydrocarbon conversion process in the catalytic systems it is necessary to use a circulating bed of filler. During the study the simplified option of circulating bed is investigated. Within simplified option catalytic filler and burning gas move only co-directional during reaction. To make the description of non-stationary heat exchange processes during the catalytic system there was suggested changed elementary balances method. Within the mathematical modeling next elements were developed: description of the variation of the gas composition in the length of the catalytic system; element of the movement of catalyst and the pressure loss of the gas flow; element describing the change of the catalytic system internal temperature. In the process of a computer experiment on a worked-out mathematical model, the graph of dependence and two-factor nonlinear regression model were obtained. The graph and model reflect the effect of the catalytic system length and the mass flow rate of burning gas on average hydrocarbon content at the outlet of the catalytic system. Dependences obtained during the mathematical modeling were validated in experimental studies. To reach a high conversion of hydrocarbons it is necessary to provide prolonged contact of the burning gas and the catalytic filler by increasing the length of the investigated catalytic system, by using gas with low hydrocarbon content or by creating a combination of narrow channels, each of which provides the desired flow rate.

Keywords: Circulating fluidized bed, chemical reactors, hydrocarbons, non-stationary mode, mathematical modeling, experimental validation.

\section{INTRODUCTION}

At present, various designs of catalytic combustion devices have been developed. The majority of designs include a stationary bed of catalytic filler, through which burnt mixture is passed. However, due to the exothermic reaction of hydrocarbon combustion in the part of a stationary bed of a catalyst "hot spots" with temperatures above $1500^{\circ} \mathrm{C}$ arise. That can cause gradual destruction of the catalytic filler and the failure of all catalytic system [8]. In this regard, the usage of catalytic systems is a complex technical issue, in the frame of which it is important to use a special design of catalytic system.

To prevent the erosion of the filler in several catalytic burners the high temperature catalytic agents are used, particularly in the work [20] it is proposed to use sintered metal particles coated with high-porous ceramic layers. The use of hightemperature catalytic devices is justified in the case when higher temperature level is needed (up to $500 \ldots 600 \mathrm{oC}$ ), although in this case there is a significant increase of nitrogen oxides (NOx) quantity in exhaust gases. 
To reduce the temperature of catalytic filler and avoid its overheating controlled and distributed input of fuel and oxidizer (oxygen) is used. In particular, the work [15] proposes a catalytic combustion device with the introduction of oxygen in two stages. However, the usage of such catalytic devices requires complex systems with distributed input of oxidant and fuel, as well as a complex system of regulating the amount of introduced fuel and oxidizer in every part of the catalytic system.

To reduce the temperature of catalytic filler up to necessary values additional external cooling is used. In particular, the work [8] describes catalytic burners with the usage of the external water cooling. However, the usage of such catalytic devices creates a difference between the inside temperature of the filler from the center to its edges, that is connected with the necessity of intensive cooling device combustion. As a result, there is cooling of peripheral layers of filler until the stop of combustion process.

To cool the filler the work [18] proposes to use extra internal cooling with the help of tubular ceramic catalytic burning device with inside aluminum heat exchanger attended by heat. However, the usage of such catalytic devices requires complex heat exchangers and the need to adjoin them according to their heat.

The articles $[3,4]$ provides a description of various embodiments of catalytic reactors with a fixed bed of a catalytic filler.

A certain group is devices that do not work in the stationary mode. In connection with the formation of combustion front (cooling) in a stationary bed of a catalyst at low concentrations of fuel mixture «reverse-process» was proposed. That allows to transform the direction of the front into back one when changing the direction of fuel-oxidizer mixture inputting, as a result, non-stationary burning mode is created in the device $[9 ; 11,12,14]$. However, such catalytic systems require a complex reverse flow system, which should be able to function at high temperatures up to $600 \mathrm{oC}$.

Intermediate place between catalytic devices operating in the stationary regime, and devices operating in the non-stationary regime, is taken by the devices with fluidized bed of catalytic filler. The paper [19] presents the comparative study between fluidized bed and fixed bed reactors and describes some of the advantages of rectors with fluidized bed. The work [6] describes catalytic heat generator with fluidized bed and built-in heat-exchange devices. The studies [1, $2,5]$ devoted to the use of catalytic systems with fluidized bed in various chemical processes. Use fluidized bed allows to organize mixing of catalytic filler, but the intensity of this mixing is low. When catalyst bed increases, only the top of the bed is boiling. Also in fluidized bed there is a possibility of channel formation through which considerable amounts of combustible mixture can pass, almost without interacting with filler.

Thus, the current designs of catalytic systems have their drawbacks primarily connected with insufficiently intensive usage of expensive catalytic filler. To increase the intensity of the hydrocarbon conversion process in the catalytic systems $[10,16]$ proposed to use a circulating bed of filler. As a result, the filler is circulated within the catalytic system that completely eliminates the situation of inefficient use of catalytic filler. Therefore, currently catalytic systems with the circulating bed of filler are the most perspective,

\section{MATERIALS AND METHODS}

Due to the fact that at present the most perspective catalytic system is considered the one with non-stationary bed of filler, mathematical modeling of functioning of the catalytic system with movable filler was carried out. To investigate functioning features of the catalytic system with the moving filler the scheme (Figure 1) of filler movement within the catalytic system is proposed. Burning gas is introduced from the bottom of the catalytic system directly into the riser pipe. At movement on the riser pipe burning gas carries with it the catalytic filler. In the process of the joint motion hydrocarbons are burned. At the end of the riser pipe the exhaust gases are removed from the catalytic system and the filler under gravity are returned to the beginning of the riser. Thus, the simplified option of circulating bed is investigated. Within simplified option catalytic filler and burning gas move only co-directional during reaction.

Within the modeling the important task was an adequate description of non-stationary processes in the framework of the studied system. To solve the non-stationary problems existing numerical methods can be used, especially finite difference method, elementary heat balance method, finite element method [7, 13]. However, the usage of the methods to describe the processes of functioning of the catalytic system is 
complicated by the following peculiarities of the observable process: complex geometrical objects which participate in the heat exchange (elementary heat balance method, finite element method) and complex description of initial conditions (finite element method) connected with a significant quantity of moving catalytic filler.

To make the description of non-stationary heat exchange processes during the catalytic system operation there was suggested changed elementary balances method. That method means that the catalytic system is divided into elementary geometrical shapes, in the range of each shape the temperature is equal. Current heat values (average for elementary time period) are taken as proportional to initial temperature gradient for the certain time period, and increase of heat volume content is taken as proportional to increase of its temperature. That allows to restrict heat impact of catalytic filler with elementary volume where they are located in the initial moment of elementary time period.

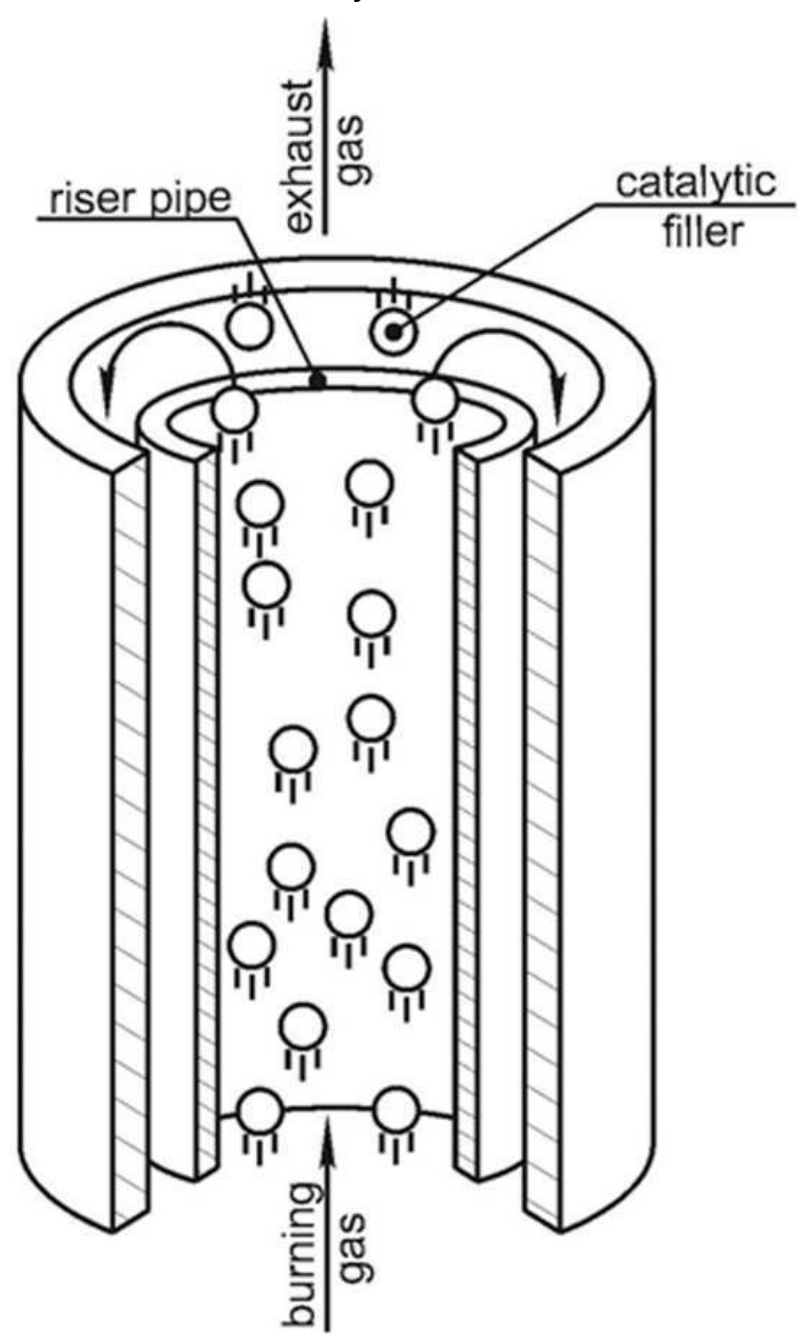

Figure 1: The scheme of co-directional movement of the filler and burning gas within the catalytic system

To illustrate the processes of functioning of the catalytic system the mathematical model was developed with the help of Microsoft Excel and Visual Basic. The detailed description of the developed mathematical model presented in the paper [17].

Within the mathematical modeling different elements of model were developed. The first model element describes the variation of the gas composition in the length of the catalytic system based on the dependency of the interaction of the catalyst and reaction mixture. The second element of model is devoted to the movement of catalyst and the pressure loss of the gas flow on the basis of the equations for the forces acting on the catalyst during the movement. The last model element describes the change of the catalytic system internal temperature based on heat balances for the elementary parts of the system. 
In accordance with the selected range of variation of the input factors (Table 1) mathematical modeling of functioning of hydrocarbon catalytic combustion system with co-directional movement of the filler and the burning gas was carried out.

Table 1: The range of variation of input factors of computer experiment in the studied area

\begin{tabular}{|c|c|c|}
\hline № & Factor & $\begin{array}{c}\text { Range of } \\
\text { variation }\end{array}$ \\
\hline 1 & $\begin{array}{c}\text { length of the catalytic } \\
\text { system (m) }(\mathrm{X} 1)\end{array}$ & $0,5-5$ \\
\hline 2 & $\begin{array}{c}\text { burning gas mass flow } \\
(\mathrm{kg} / \mathrm{s})(\mathrm{X} 2)\end{array}$ & $0,00018-0,18$ \\
\hline
\end{tabular}

To confirm the reliability of the data obtained by mathematical modeling the experimental studies of functioning features were carried out on the developed equipment presented in Figure 2.

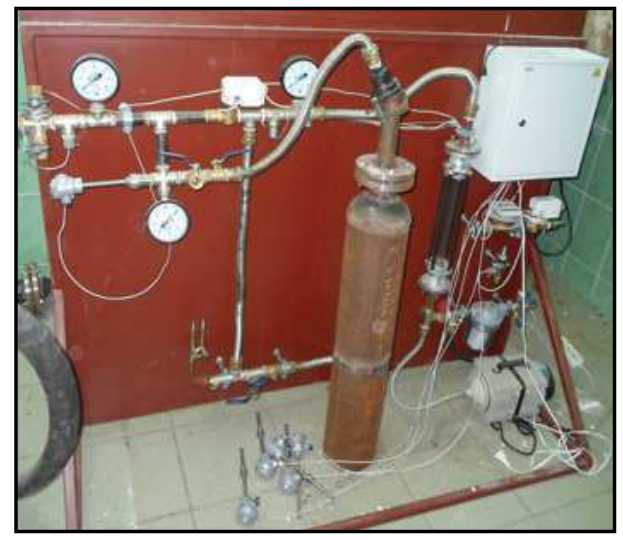

Figure 2: The experimental equipment for the study of the functioning of the catalytic combustion system

The experimental studies of the functioning of the hydrocarbon catalytic combustion system with co-directional movement of the filler and the burning gas were conducted in accordance with the plan presented in Table 2.

Table 2: The plan of experimental studies of functioning of the hydrocarbon catalytic combustion system with co-directional movement of the filler and the burning gas

\begin{tabular}{|c|c|c|c|c|}
\hline \multirow{2}{*}{\multicolumn{2}{|c|}{$\begin{array}{c}\text { № of experiment } \\
\text { series }\end{array}$}} & \multicolumn{3}{|c|}{$\begin{array}{c}\text { The burning gas mass } \\
\text { flow }(\mathrm{kg} / \mathrm{s})\end{array}$} \\
\hline & & \multirow{2}{*}{$\begin{array}{c}0,002 \\
\mathrm{~kg} / \mathrm{s}\end{array}$} & \multirow{2}{*}{$\frac{0,003}{\mathrm{~kg} / \mathrm{s}}$} & \multirow{2}{*}{$\begin{array}{c}0,004 \\
\mathrm{~kg} / \mathrm{s} \\
\mathrm{III}\end{array}$} \\
\hline 잉 & $0,4 \mathrm{~m}$ & & & \\
\hline 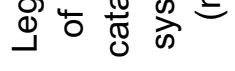 & $0,5 \mathrm{~m}$ & IV & V & VI \\
\hline
\end{tabular}

\section{RESULTS}

In the process of computer experiment on the developed mathematical model a graph of dependence was obtained, which is shown in Figure 3 , reflecting the effect of the length of the catalytic system and mass flow rate of burning gas on average hydrocarbon content at the outlet of the catalytic system.

Statistical analysis of the results of computer simulation showed that the dependence of the average hydrocarbon concentration at the outlet of the catalytic system on the input factors "length of the catalytic system" and "the mass flow rate of burning gas" can be described by two-factor nonlinear regression model:

$$
\begin{aligned}
& \text { av. } H C=-0.0195-0.3412^{*} \mathrm{G}-0.039^{*} \mathrm{~L}+(0.01155+ \\
& \left.+0.0185^{*} \mathrm{~L}\right)^{*} \log \left(0.99+224.467^{*} \mathrm{G}\right),
\end{aligned}
$$

where av. $\mathrm{HC}$ - average hydrocarbon content at the outlet of the catalytic system, \%; $L$ - length of the catalytic system, m; G - mass flow rate of burning gas, kg/s.

According to the results of the full-scale experiment, the graphs of the dependence of the hydrocarbon concentration at the outlet of the catalytic system (av.HC) (averaged during the functioning period of the equipment) on the mass flow rate of burning gas were obtained. The graphs are presented in Figure 4. According to the results of comparison with the mathematical modeling data, under respective conditions an error does not exceed $10 \%$. That fact allows to make a conclusion that the data obtained by mathematical modeling are valid.

\section{DISCUSSIONS}

The objective of this study was to research the features of functioning of the catalytic system with co-directional movement of the filler and the burning gas. The obtained dependence (Figure 3 ) allows to establish that with the increase of the length value of the catalytic system average hydrocarbon content at the outlet of the catalytic system decreases linearly, due to the fact that the catalytic system of greater length can utilize more hydrocarbons. With the increase of mass flow of burning gas the average hydrocarbon content at the outlet of the catalytic system increases not linearly and the growth slows down when values are higher, due to the fact that large volumes of gas lead to less efficient conversion process of hydrocarbons and increase of hydro- 
carbon content up to very close to the initial one. The minimum value of the average hydrocarbon concentration at the outlet of the catalytic system is observed at the maximum length of the catalytic system and the minimum value of the mass flow rate of burning gas.

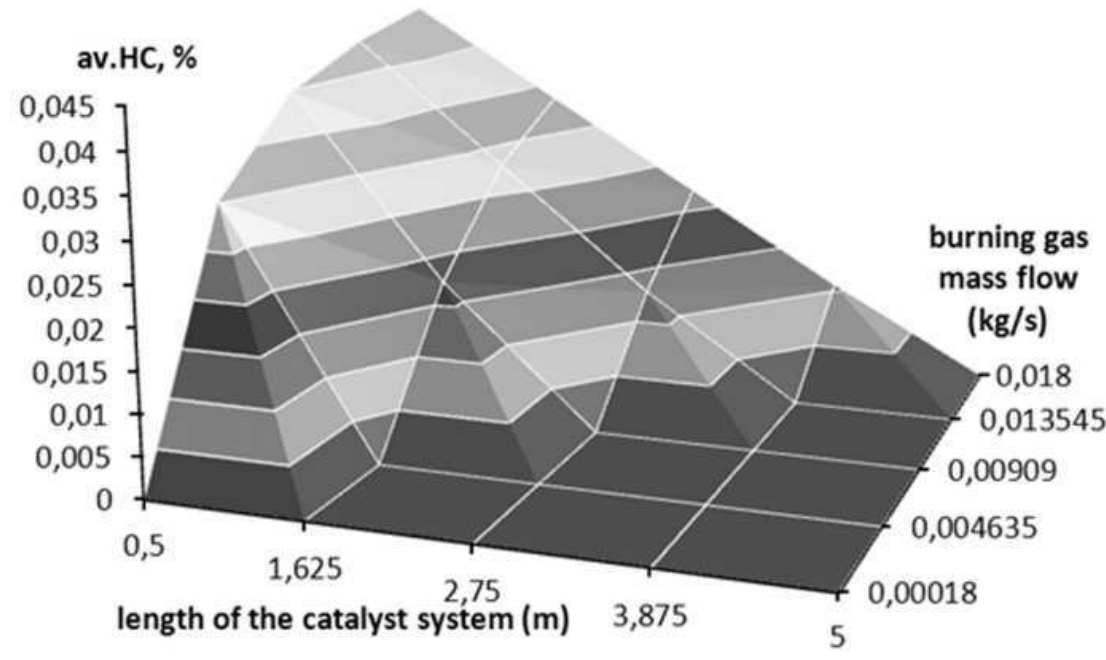

Figure 3: Graph of dependence of the average hydrocarbon concentration at the outlet of the catalytic system in a computer experiment on the length of the catalytic system $(\mathrm{m})$ and the burning gas mass flow $(\mathrm{kg} / \mathrm{s})$
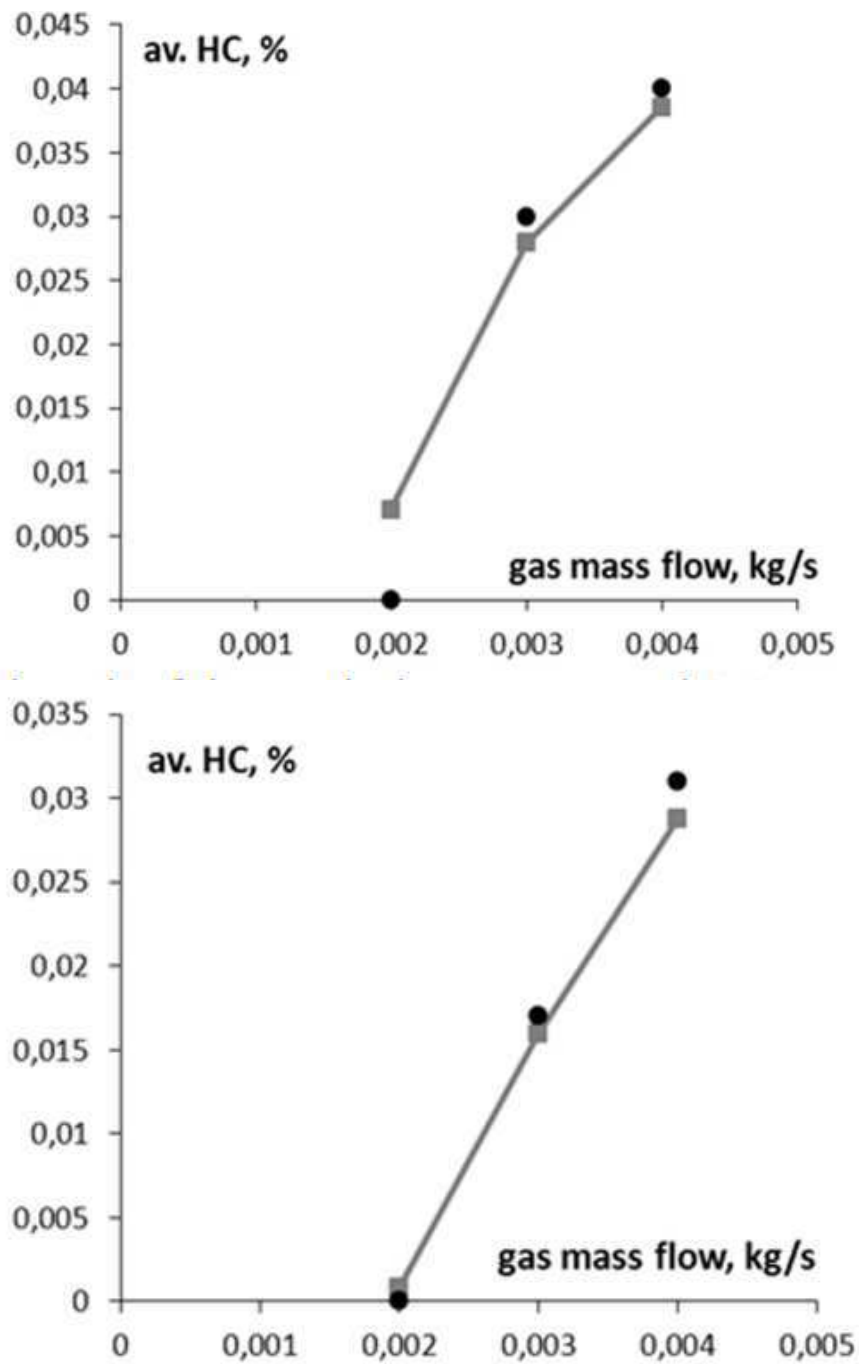

Figure 4: Dependence graphs of the average hydrocarbon concentration at the outlet of the catalytic system (av. HC) on the mass flow rate of burning gas:

experimental data; $\longrightarrow$ - data obtained using a mathematical model 
On the contrary, the maximum value of the average hydrocarbon concentration at the outlet of the catalytic system is observed at the minimum length of the catalytic system and the maximum value of the mass flow rate of burning gas.

Thus, to provide complete conversion of the burning component of the gas it is necessary to create conditions for long interaction of the combustion mixture and moving filler by increasing the length of the catalytic system. This feature is determined by the characteristics of the catalytic system with co-directional movement of the filler and the burning gas.

There are no requirements for specific speed of movement of the filler when catalytic systems with fixed bed of filler are used. It is necessary to provide specific parameters of pressure to pass burning gas through the filler $[8,15,20]$. Using of the fluidized bed of filler requires a specific flow rate of burning gas, which generates fluctuation of the catalyst particles, i.e. fluidizes bed of filler $[1,5,6]$. Using of the circulating bed filler implies a significant increase of the flow rate of burning gas which carries with it the catalytic filler $[16,17]$. Therefore the circulating bed systems are the most demanding of the flow rate of burning gas.

Thus, it is necessary to supply significant volumes of combustion gas for high flow rate in the investigated system with co-directional movement of the filler and the burning gas.

Under these conditions to reach a high conversion of hydrocarbons it is necessary to provide prolonged contact of the burning gas and the filler by increasing the length of the catalytic system, by using gas with low hydrocarbon content or by creating a combination of narrow channels, each of which provides the desired flow rate.

\section{CONCLUSIONS}

Current designs of catalytic systems have their drawbacks, primarily connected with insufficiently intensive usage of expensive catalytic filler. To increase the intensity of the hydrocarbon conversion process in the catalytic systems it is necessary to use a circulating bed of filler. During the study the simplified option of circulating bed is investigated. Within simplified option catalytic filler and burning gas move only co-directional during reaction. The graph and model reflecting the effect of the catalytic system length and the mass flow rate of burning gas on average hydrocarbon content at the outlet of the catalytic system were obtained. According to the results of comparison with the experimental study data, under respective conditions an error does not exceed $10 \%$. To reach a high conversion of hydrocarbons it is necessary to provide prolonged contact of the burning gas and the filler by increasing the length of the catalytic system, by using gas with low hydrocarbon content or by creating a combination of narrow channels, each of which provides the desired flow rate.

\section{REFERENCE}

1) Asadullaha, M., Itoa, S., Kunimoria, K., Yamadab, M. \& Tomishigea, K., (2002) Biomass gasification to hydrogen and syngas at low temperature: novel catalytic system using fluidized-bed reactor, Journal of Catalysis, 208, 255-259. DOI: 10.1006/ jcat.2002.3575

2) Author, Author, Author, Author, (2012) Improving the efficiency of the developed catalytic systems for biogas utilization, Scientific Journal of KubSAU, 4(78), 528-541.

3) Chan, L.K., Sarofim, A.F. \& Beer, J.M., (1983) Kinetics of the NO-carbon reaction at fluidized bed combustor conditions, Combustion and Flame, 52, 37-45. DOI: 10.1016/0010-2180(83)90119-0

4) Hannemanna, S., Grunwaldta, J.-D., van Vegtena, N., Baikera, A., Boyeb, P. \& Schroerb, C.G., (2007) Distinct spatial changes of the catalyst structure inside a fixed-bed microreactor during the partial oxidation of methane over Rh/Al2O3, Catal. Today, 126, 54-63. DOI: 10.1016/ j.cattod.2006.08.065

5) Hannemanna, S., Grunwaldta, J.-D., van Vegtena, N., Baikera, A., Boyeb, P. \& Schroerb, C.G., (2007) Distinct spatial changes of the catalyst structure inside a fixed-bed microreactor during the partial oxidation of methane over $\mathrm{Rh} / \mathrm{Al} 2 \mathrm{O} 3$, Catal. Today, 126, 54-63. DOI: 10.1016/ j.cattod.2006.08.065

6) lamarinoa, M., Chironeb, R., Lisib, L., Pironeb, R., Salatinoc, P. \& Russob, G. (2002) $\mathrm{Cu} / \mathrm{y}-\mathrm{Al} 2 \mathrm{O} 3$ catalyst for the combustion of methane in a fluidized bed reactor, Catal. Today, 75, 317-324. DOI: 10.1016/S09205861(02)00084-6

7) Kutateladze, S.S. \& Borishansky, V.M., (1958) Handbook of Heat Transfer, Moscow: GEl. 
8) Lukyanov, B.N., Kuzin, N.A., Kirillov, V.A., Kulikov, V.A. \& Shigarov, V.B., (2001) Cleaner oxidation of hydrocarbon gases in the catalytic heating elements, Chemistry for Sustainable development, 9, 667-677.

9) Matros, Yu.Sh., Noskov, A.S. \& Chumachenko, V.A., (1993) Progress in reverseprocess application to catalytic incineration problems, Chem. Eng. Sci., 32, 89-98. DOI: 10.1016/0255-2701(93)85019-C

10)Nieke, U., Kolios, G. \& Eigenberger, G., (1994) Fixed-bed reactors with periodic flow reversal: experimental results for catalytic combustion, Catal. Today, 20, 335-350. DOI: 10.1016/0920-5861(94)80130-4

11)Noskov, A.S., (1997), Catalytic purification of gases from organic impurities and oxides of nitrogen in the mode of moving heat wave, Physics of combustion and explosion, 3 (33), 49-60.

12)Patankar, S., (1984), Numerical methods for solving heat transfer and fluid dynamics, Moscow: Energoatomizdat.

13)Salomonsa, S., Hayesa, R.E., Poirierb, M. \& Sapoundjievb, H., (2003) Flow reversal reactor for the catalytic combustion of lean methane mixtures, Catal. Today, 83, 59-69. DOI: 10.1016/S0920-5861(03)00216-5

14)Shikong, S., Zhiyong, P., Chaoyang, D., Qiying, J., Zhaobin, Z. \& Changchun, Y. (2000),
A novel two-stage process for catalytic oxidation of methane to synthesis gas, Ranliao Huaxue Xuebao, 4, 348. DOI: 10.1016/ S0167-2991(01)80287-1

15)Theophilos, P. \& Xenophon, V., (1998) Development of a novel heat-integrated wall reactor for the partial oxidation of methane to synthesis gas, Catal. Today, 46, 71-81. DOI: 10.1016/S0920-5861(98)00328-9

16) Tomishige, K., Matsuo, Y., Yoshinaga, Y., Sekine, Y., Asadullah, M. \& Fujimoto, K. (2002). Comparative study between fluidized bed and fixed bed reactors in methane reforming combined with methane combustion for the internal heat supply under pressurized condition, Applied Catalysis A: General, 223, 225-238. DOI: 10.1016/ S0926-860X(01)00757-8

17) van Giezen, J.C., Intven, M., Meijer, M.D., Geusa, J.W., Mulderb, A., Riphagenb, G.J. \& Brouwerb, J.P., (1999) The development of novel metal-based combustion catalysts, Catal. Today, 47, 191-197. DOI: 10.1016/ S0920-5861(98)00299-5

Paper sent to revision: 27.07.2015.

Paper ready for publication: 01.04.2016. 